\title{
A mitochondrial DNA variant at position 16189 is associated with type 2 diabetes mellitus in Asians
}

\author{
K. S. Park • J. C. Chan • L.-M. Chuang • S. Suzuki • \\ E. Araki $\cdot$ K. Nanjo $\cdot$ L. Ji $\cdot$ M. Ng $・$ M. Nishi $\cdot$ \\ H. Furuta • T. Shirotani $\cdot$ B. Y. Ahn $\cdot$ S. S. Chung • \\ H.-K. Min • S. W. Lee • J. H. Kim • Y. M. Cho • \\ H. K. Lee • for The Study Group of Molecular \\ Diabetology in Asia
}

Received: 7 November 2007 / Accepted: 1 January 2008/Published online: 5 February 2008

(C) Springer-Verlag 2008

\begin{abstract}
Aims/hypothesis This multinational study was conducted to investigate the association between a mitochondrial DNA (mtDNA) T16189C polymorphism and type 2 diabetes in Asians. The mtDNA $16189 \mathrm{C}$ variant has been reported to be associated with insulin resistance and type 2 diabetes. However, a recent meta-analysis concluded that it is negatively associated with type 2 diabetes in Europids. Since
\end{abstract}

Electronic supplementary material The online version of this article (doi:10.1007/s00125-008-0933-z) contains supplementary material, which is available to authorised users.

K. S. Park $\cdot$ B. Y. Ahn $\cdot$ S. S. Chung

J. H. Kim $•$ Y. M. Cho $\cdot$ H. K. Lee

Department of Internal Medicine,

Seoul National University College of Medicine,

Seoul, South Korea

K. S. Park • B. Y. Ahn $\cdot$ S. S. Chung $\cdot$ J. H. Kim $\cdot$ Y. M. Cho Genome Research Center for Diabetes and Endocrine Disease, Clinical Research Institute, Seoul National University Hospital, Seoul, South Korea

J. C. Chan $\cdot$ M. Ng

Department of Medicine and Therapeutics,

Prince of Wales Hospital, The Chinese University of Hong Kong,

Shatin, Hong Kong SAR, China

L.-M. Chuang

Division of Endocrinology and Metabolism, Department of

Internal Medicine, National Taiwan University Hospital,

Taipei, Taiwan

\section{S. Suzuki}

Department of Internal Medicine,

Division of Molecular Metabolism and Diabetes,

Tohoku University Graduate School of Medicine,

Sendai, Japan the phenotype of an mtDNA mutant may be influenced by environmental factors and ethnic differences in the nuclear and mitochondrial genomes, we investigated the association between the $16189 \mathrm{C}$ variant and type 2 diabetes in Asians. Methods The presence of the mtDNA 16189C variant was determined in 2,469 patients with type 2 diabetes and 1,205 non-diabetic individuals from Korea, Japan, Taiwan, Hong Kong and China. An additional meta-analysis including

\section{E. Araki $\cdot$ T. Shirotani}

Department of Metabolic Medicine, Graduate School of Medical and Pharmaceutical Sciences, Kumamoto University,

Kumamoto, Japan

K. Nanjo $\cdot$ M. Nishi $\cdot$ H. Furuta

The First Department of Medicine,

Wakayama Medical University,

Wakayama, Japan

L. Ji

Department of Endocrinology and Metabolism,

People's Hospital, Peking University,

Beijing, China

H.-K. Min • S. W. Lee

Department of Chemistry and Center for Electro- and

Photo-Responsive Molecules, Korea University,

Seoul, South Korea

H. K. Lee $(\bowtie)$

Department of Internal Medicine,

Seoul National University College of Medicine,

28 Yongon-Dong Chongno-Gu,

Seoul 110-744, South Korea

e-mail: hkleemd@snu.ac.kr 
previously published Asian studies was performed. Since mtDNA nucleotide position 16189 is very close to the mtDNA origin of replication, we performed DNA-linked affinity chromatography and reverse-phase liquid chromatography/tandem mass spectrometry and chromatin immunoprecipitation to identify protein bound to the 16189 region. Results Analysis of participants from five Asian countries confirmed the association between the $16189 \mathrm{C}$ variant and type 2 diabetes [odds ratio (OR) $1.256,95 \%$ CI $1.08-1.46$, $p=0.003]$. Inclusion of data from three previously published Asian studies (type 2 diabetes $n=3,283$, controls $n=2,176$ ) in a meta-analysis showed similar results (OR 1.335, 95\% CI 1.18-1.51, $p=0.000003$ ). Mitochondrial single-stranded DNA-binding protein (mtSSB) was identified as a candidate protein bound to the 16189 region. Chromatin immunoprecipitation in cybrid cells showed that mtSSB has a lower binding affinity for the $16189 \mathrm{C}$ variant than the wild-type sequence.

Conclusions/interpretation The mtDNA $16189 \mathrm{C}$ variant is associated with an increased risk of type 2 diabetes in Asians.

Keywords 16189 Variant · Asian · Mitochondrial DNA . Mitochondrial single-stranded DNA-binding protein .

Polymorphism · Type 2 diabetes

$\begin{array}{ll}\text { Abbreviations } \\ \text { ChIP } & \begin{array}{l}\text { chromatin immunoprecipitation } \\ \text { green fluorescent protein }\end{array} \\ \text { GFP } & \begin{array}{l}\text { reverse-phase liquid chromatography/ } \\ \text { tandem mass spectrometry }\end{array} \\ \text { mtDNA } & \begin{array}{l}\text { mitochondrial DNA } \\ \text { mitochondrial single-stranded } \\ \text { mtSSB }\end{array} \\ \text { DNA-binding protein } \\ \text { np } & \begin{array}{l}\text { nucleotide position } \\ \text { OR }\end{array}\end{array}$

\section{Introduction}

Mitochondrial dysfunction plays a critical role in the pathogenesis of insulin resistance and diabetes mellitus [1]. Mutations in mitochondrial DNA (mtDNA) have been reported to be a cause of maternally inherited diabetes mellitus [2] and a cluster of features of the metabolic syndrome [3]. The cytosine for thymidine substitution $(\mathrm{T} \rightarrow \mathrm{C})$ at nucleotide position (np) 16189, which lies in the mtDNA control region for replication and transcription, has been reported to be associated with insulin resistance and type 2 diabetes [4-9]. Despite these findings, a recent meta-analysis of European studies concluded that the $16189 \mathrm{C}$ variant was not associated with type 2 diabetes in Europids [10].
Since type 2 diabetes is a common, complex disease influenced by both genetic and environmental factors, the result of the European study [10] may not be applicable to other ethnic groups with different genetic backgrounds who are subjected to different environmental factors. For example, the $16189 \mathrm{C}$ variant is found at a higher frequency in Asians than in Europids [11]. In light of the rapid increase in diabetes and the metabolic syndrome in Asia, we examined the association between the $16189 \mathrm{C}$ variant and type 2 diabetes in Asians, in a multinational study.

\section{Methods}

Participants Five Asian countries (Korea, Japan, Taiwan, China and Hong Kong) participated in this case-control study. We recruited 2,469 patients with type 2 diabetes and 1,205 non-diabetic controls (Table 1). The diagnosis of type 2 diabetes was made by diabetologists using the WHO criteria [12]. The following criteria were used to define the control subjects: no history of diabetes, a fasting plasma glucose level of $<6.1 \mathrm{mmol} / 1$ and an $\mathrm{HbA}_{1 \mathrm{c}}$ value of $<5.8 \%$.

Table 1 Characteristics of the study population

\begin{tabular}{|c|c|c|}
\hline & $\begin{array}{l}\text { Patients with type } 2 \\
\text { diabetes }(n=2,469)\end{array}$ & $\begin{array}{l}\text { Non-diabetic } \\
\text { controls }(n=1,205)\end{array}$ \\
\hline \multicolumn{3}{|l|}{ China } \\
\hline$n$ & 383 & 102 \\
\hline Age (years) & $58 \pm 11$ & $47 \pm 9$ \\
\hline $\operatorname{Sex}(M / F)$ & $205: 178$ & $49: 53$ \\
\hline BMI $\left(\mathrm{kg} / \mathrm{m}^{2}\right)$ & $25.1 \pm 4.3$ & $24.0 \pm 3.2$ \\
\hline \multicolumn{3}{|l|}{ Hong Kong } \\
\hline$n$ & 504 & 170 \\
\hline Age (years) & $40 \pm 7$ & $33 \pm 8$ \\
\hline $\operatorname{Sex}(M / F)$ & $200: 304$ & $67: 103$ \\
\hline BMI $\left(\mathrm{kg} / \mathrm{m}^{2}\right)$ & $25.7 \pm 5.5$ & $22.5 \pm 4.8$ \\
\hline \multicolumn{3}{|l|}{ Japan } \\
\hline$n$ & 535 & 380 \\
\hline Age (years) & $64 \pm 13$ & $73 \pm 8$ \\
\hline $\operatorname{Sex}(M / F)$ & $283: 252$ & $123: 257$ \\
\hline BMI $\left(\mathrm{kg} / \mathrm{m}^{2}\right)$ & $23.4 \pm 3.9$ & $22.6 \pm 3.3$ \\
\hline \multicolumn{3}{|l|}{ Korea } \\
\hline$n$ & 643 & 469 \\
\hline Age (years) & $59 \pm 10$ & $64 \pm 6$ \\
\hline $\operatorname{Sex}(M / F)$ & $311: 332$ & $181: 288$ \\
\hline BMI $\left(\mathrm{kg} / \mathrm{m}^{2}\right)$ & $24.5 \pm 2.9$ & $23.2 \pm 3.0$ \\
\hline \multicolumn{3}{|l|}{ Taiwan } \\
\hline$n$ & 404 & 84 \\
\hline Age (years) & $60 \pm 10$ & $54 \pm 11$ \\
\hline $\operatorname{Sex}(\mathrm{M} / \mathrm{F})$ & 193:211 & $51: 33$ \\
\hline BMI $\left(\mathrm{kg} / \mathrm{m}^{2}\right)$ & $24.6 \pm 3.2$ & $24.4 \pm 4.5$ \\
\hline
\end{tabular}

Continuous variables are expressed as means \pm SD 
The study was approved by the ethics committee of the participating institutions and all the study participants gave written informed consent.

Genetic analysis The presence of the mtDNA 16189C variant was determined by PCR and MnlI digestion, as previously described [6]. DNA was extracted from peripheral blood leucocytes. The forward PCR primer was 5'-CCATT AGCACCCAAAGCTAA-3' (15980-15999) and the reverse primer was 5'-GTAATGTGCTATGTACGGTA-3' (1634416325). The PCR product ( $365 \mathrm{bp}$ ) was digested with $1 \mathrm{U}$ of MnlI for $2 \mathrm{~h}$ at $37^{\circ} \mathrm{C}$ and was subjected to electrophoresis on a $2 \%$ agarose gel with both positive and negative controls. There were 290 PCR products directly sequenced using the ABI 373 sequencer (Applied Biosystems, Foster City, CA, USA), and $99 \%(287 / 290)$ of the sequencing results were in agreement with those obtained by gel electrophoresis.

Proteomic analysis by DNA-linked affinity chromatographyliquid chromatography/tandem mass spectrometry To identify the protein bound to the 16189 region of mtDNA, we performed DNA-linked affinity chromatography and reversephase liquid chromatography/tandem mass spectrometry (LC/MS/MS), as previously described [13].

Oligonucleotides (36 bp) representing an mtDNA region flanking 16189T (light strand: 5'-CCAACCCACATCAAAC CCCCTCCCCCATGCTTACAA-3', 5'-amine modified) were hybridised with the corresponding oligomers (heavy strand). The oligomers ( $84 \mathrm{nmol}$ ) were coupled to $\mathrm{N}$ hydroxysuccinimide (NHS)-activated Sepharose 4 Fast Flow (Amersham Biosciences, Piscataway, NJ, USA). The oligomer-resin complex was incubated with mitochondrial extracts $(2 \mathrm{mg})$ in $25 \mathrm{mmol} / 1$ Tris, $\mathrm{pH} 7.4,1 \mathrm{mmol} / 1$ EDTA and $250 \mathrm{mmol} / 1$ sucrose, and washed with the same buffer supplemented with $1 \mathrm{mmol} / \mathrm{l}$ phenylmethylsulphonyl fluoride and $0.5 \mathrm{mg} / \mathrm{ml}$ poly $(\mathrm{dI}-\mathrm{dC})$. Proteins bound to the resin were eluted with $0.05 \%$ trifluoroacetic acid and analysed by LC/MS/MS. Briefly, a quadrupole ion trap mass spectrometer (LCQ; ThermoFinnigan, San Jose, CA, USA) online coupled to a high-pressure capillary reversed-phase liquid chromatography system [14] was used to analyse proteins bound to the 16189 region. The mass spectrometry data from LC/MS/MS experiments were analysed using the SEQUEST program (ThermoFinnigan) against a database that was constructed by combining the IPI human database (version 3.01; ftp://ftp.ebi.ac.uk/pub/databases/IPI/current, accessed in January 2008) and the sequences of common contaminant proteins such as trypsin and keratin. Details of the peptide identification method are described elsewhere [13].

Plasmid construction, cybrid cell lines and transient transfection DNA fragments representing the human DC50 and mitochondrial single-stranded DNA-binding protein (mtSSB) genes were inserted into the plasmid pEGFP-N1 (Clontech, Mountain View, CA, USA), which contains the gene for green fluorescent protein (GFP), and the resulting vectors were named pEGFP-DC50 and pEGFP-mtSSB, respectively. Cybrid cell lines containing 16189T or 16189C were established as described previously [15]. Cybrid cells were transfected with pEGFP-DC50 or pEGFP-mtSSB by LipofectAMINE Plus reagents (Invitrogen, Carlsbad, CA, USA). Levels of the fusion proteins DC50-GFP and mtSSB-GFP, were determined by Western blot analysis, and mitochondrial targeting of these proteins was determined by immunocytochemistry.

Chromatin immunoprecipitation Chromatin immunoprecipitation (ChIP) was performed as described previously, with minor modifications [16]. After cross-linking using formaldehyde, cells were homogenised and cell extracts were fractionated by differential centrifugations [13]. The mitochondrial fraction was collected by centrifugation at $10,900 \times g$ for $3 \mathrm{~min}$, and resuspended in $25 \mathrm{mmol}$ Tris- $\mathrm{HCl}, \mathrm{pH} 7.5$, $150 \mathrm{mmol} / 1 \mathrm{NaCl}, 1 \%$ Triton X-100, $0.1 \%$ SDS, $0.5 \%$ deoxycholate and one tablet of protease inhibitors (Roche, Mannheim, Germany). The mtDNA was sheared by sonication, and the DNA-protein complexes were immunoprecipitated using $2 \mu \mathrm{g}$ of anti-mtSSB or anti-GFP antibodies (Santa Cruz Biotechnology, Santa Cruz, CA, USA). As a negative control, normal goat IgG (Santa Cruz Biotechnology) was used for immunoprecipitation. Precipitated DNA was purified, and PCR ( 25 cycles) was carried out. The sequences of the primers for the mtDNA 16189 region were: 5'-CCACCATGAATATTGTACGG-3' (16111-16130) and 5'-GGTGGCTTTGGAGTTGCAGT-3' (16260-16241); for the mtDNA 3243 region: 5'-AGGACAAGAGAAATAAG GCC-3' (3130-3149) and 5'-TGAAAGAGCGATGGTGA GAG-3' (3558-3539), for the mtDNA 5176 region: 5'CCTACTACTATCTCGCACCTG-3' (5150-5170) and 5'GTGAATTCTTCGATAATGGCC-3' (5281-5261).

Prior to immunoprecipitation, one-tenth of each extract was collected for use as a positive control for the PCR. The PCR products were visualised by electrophoresis through $2 \%$ agarose gels.

Literature searches and meta-analysis A literature search was performed by inputting the search terms 'mitochondrial DNA' and ' 16189 ' or 'poly C tract' in PubMed (January 1998 to August 2007). All studies that examined whether the $16189 \mathrm{C}$ variant is associated with type 2 diabetes in Asians were included in the present study. Meta-analysis was performed using the Comprehensive Meta Analysis (version 2) program [17]. Heterogeneity among studies was assessed using Cochran's $Q$ test. Results were considered heterogeneous if the $p$ value was $<0.10$. 


\section{Results}

Frequency of the mtDNA 16189 C variant in Asians The frequency of the $16189 \mathrm{C}$ variant was higher in type 2 diabetic patients than non-diabetic subjects (35.3\% vs $31.0 \%$; Fig. 1). The $16189 \mathrm{C}$ variant was significantly associated with type 2 diabetes mellitus [odds ratio (OR) 1.256, 95\% CI $1.08-1.46, p=0.003$; Fig. 1]. We performed a metaanalysis after combining the current data with three additional datasets from other Asian studies [7-9], to give a total of 3,283 cases with diabetes and 2,176 controls (Fig. 1). In the fixed effect meta-analysis, the $16189 \mathrm{C}$ variant was significantly associated with the risk of type 2 diabetes (OR $1.335,95 \%$ CI $1.18-1.51, p=0.000003$; Fig. 1). There was no between-study heterogeneity $(Q=9.634, d f=7, p=0.210)$.

Identification of proteins bound to the 16189 region of mtDNA Proteins bound to the 16189 region of mtDNA were identified by LC/MS/MS. A total of 41 proteins were identified (Electronic supplementary material Table 1). Of these, we chose DC50 and mtSSB, nucleic acid-binding proteins localised in mitochondria, to test whether these proteins have different binding affinity to the wild-type DNA and 16189C variant. DC50 (also known as SRA stemloop interacting RNA-binding protein [SLIRP]) is predominantly mitochondrial and is abundant in energy-demanding tissues such as skeletal muscle and liver. It has been suggested that this protein is involved in the regulation of lipid and energy metabolism [18]. It has been established that mtSSB is involved in stabilising D-loops and in the maintenance of mtDNA [19].

We established 11 cybrid cell lines containing $16189 \mathrm{~T}$ or $16189 \mathrm{C}$ variants using platelets as mtDNA donors [15]. Expression of the vectors pEGFP-DC50 and pEGFPmtSSB resulted in the targeting of the fusion proteins to mitochondria (data not shown). Following the transfection of expression vectors for DC50-GFP and mtSSB-GFP into $16189 \mathrm{C}$ or $16189 \mathrm{~T}$ cybrid cell lines, ChIPs were performed with anti-GFP antibodies. After immunoprecipitation with anti-GFP antibodies, PCR was performed, giving a product of $150 \mathrm{bp}$ (mtDNA 16111-16260). There was little difference between the two cell lines in terms of the binding affinity of DC50-GFP for the 16189 region (Fig. 2a). The binding affinity of mtSSB-GFP for the 16189 region in the 16189T cell line was much higher than that in the $16189 \mathrm{C}$ cell line. Since the results shown in Fig. 2a indicated the possibility that the binding affinity of mtSSB for the mtDNA could be modulated by the sequence of 16189 , we performed ChIP experiments to detect the binding affinity of endogenous mtSSB in the two cybrid cell lines. After immunoprecipitation with anti-mtSSB antibodies, PCR was performed with three primer sets whose products represent the following regions of mtDNA: 3130-3539, 5150-5261 and 16111-16260. The results revealed that mtSSB bound to the 16189 region, and binding affinities in 16189T cell lines were much higher than those in $16189 \mathrm{C}$ cell lines. No binding of mtSSB was observed with the other mtDNA regions tested (Fig. 2b). A total of 11 cell lines (five 16189T

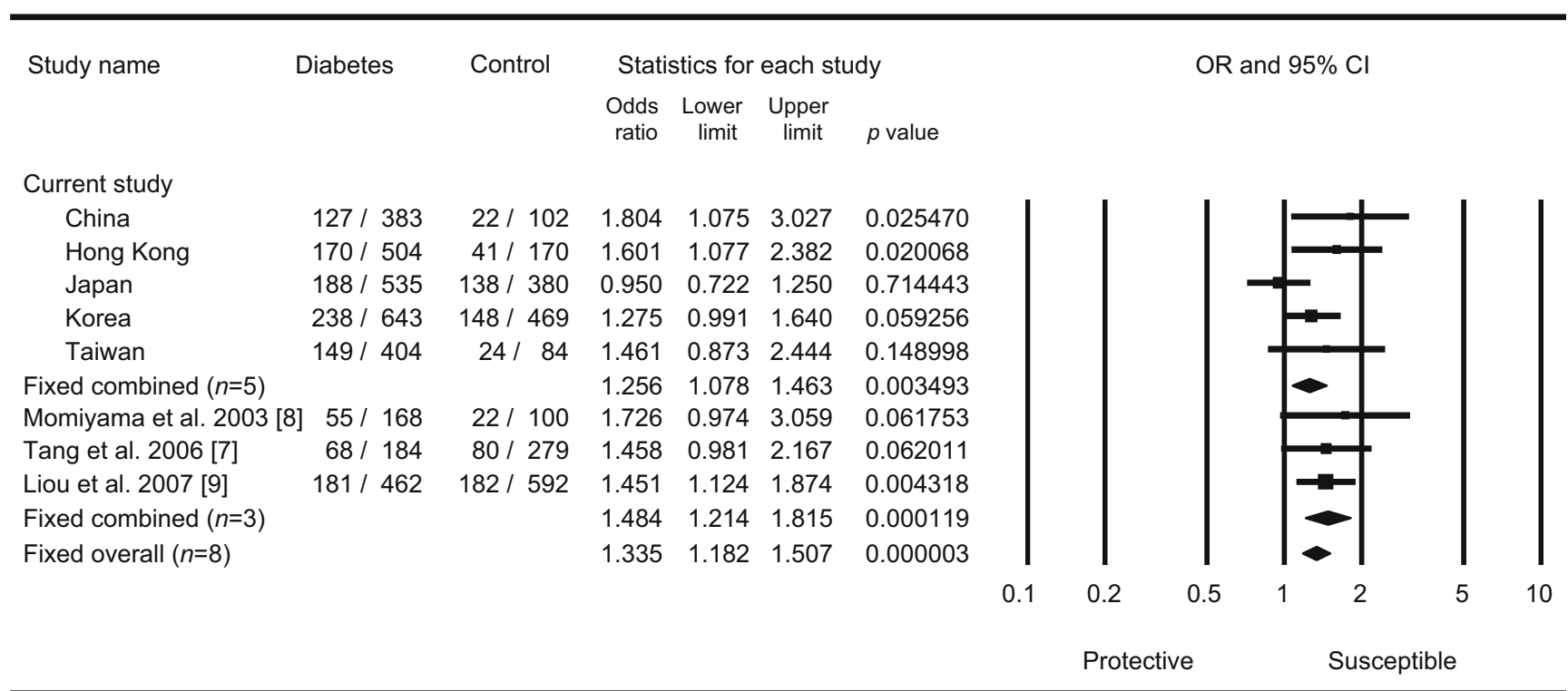

Fig. 1 Meta-analysis of the association between the $16189 \mathrm{C}$ variant and type 2 diabetes in Asian individuals. The size of the box is proportional to the size of study population. Horizontal lines indicate the $95 \%$ CI, calculated by the Mantel-Haenszel method. Each diamond represents the pooled OR, with the width representing the 95\% CI for the number of datasets indicated. The data given in the 'Diabetes' and 'Control' columns are the number of participants with the $16189 \mathrm{C}$ variant/the total number of participants 


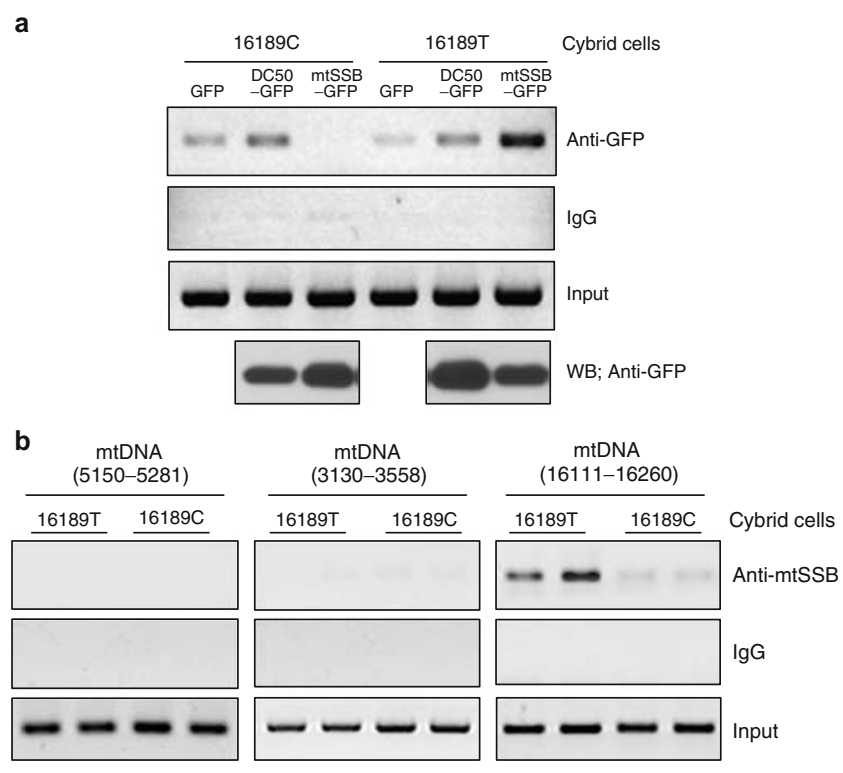

C

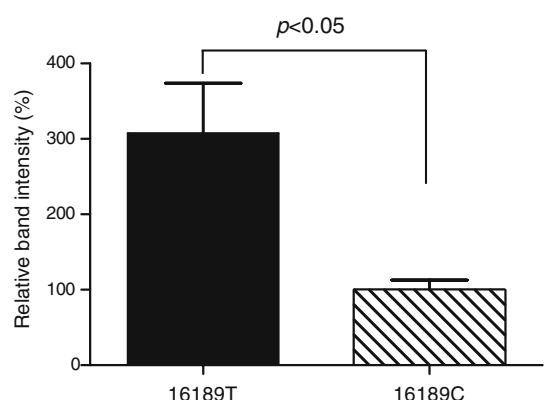

Fig. 2 ChIP analysis of mtSSB binding to the mtDNA 16189 region. a GFP (control), DC50-GFP or mtSSB-GFP was expressed in two different cybrid cell lines (containing 16189T or 16189C) by transient transfection with pEGFP, pEGFP-DC50 or pEGFP-mtSSB, respectively. Mitochondria were isolated after cross-linking, and ChIP was performed with anti-GFP antibodies as described in Methods. Immunoprecipitation was performed with normal IgG as a negative control. The 'input' gel (a positive control) shows the PCR products of samples of the mitochondrial extracts used for immunoprecipitation. Levels of DC50GFP and mtSSB-GFP were determined by Western blot analysis (WB) with anti-GFP antibodies. b Two 16189T and two 16189C cybrid cell lines were used. ChIP analysis was performed with anti-mtSSB antibodies and three different sets of primers whose PCR products represented the mtDNA regions $3130-3558,5150-5281$ or $16111-$ 16260 , were used for PCR. c Quantitation of relative band intensity of the PCR product (mtDNA 16111-16260)

and six 16189C) were tested, and mean mtSSB binding affinity was higher in the $16189 \mathrm{~T}$ cell line than in the 16189C cell line (Fig. 2c), and when each was considered individually, mtSSB showed a higher binding affinity in all except one $16189 \mathrm{~T}$ cell line (data not shown).

\section{Discussion}

In this study, we confirmed the higher frequency of the 16189C variant in Asian non-diabetic individuals (31.0\%) compared with European individuals (9.2\%) [10]. Despite the negative results in a meta-analysis of European studies [10], consistent with other studies [4, 5, 9], we found an association between the $16189 \mathrm{C}$ variant and the risk of type 2 diabetes in this multinational Asian case-control cohort.

The substitution of cytosine for thymidine at np 16189 results in a poly-cytosine tract (the 16184-16193 poly-C tract). Since the $16189 \mathrm{C}$ variant lies in the control region of mtDNA replication and transcription, it was assumed to affect mtDNA replication. A recent study has reported a novel origin of replication very close to $n p 16189$ [20]. In this regard, it is noteworthy that mtSSB binds to $16189 \mathrm{~T}$ and $16189 \mathrm{C}$ with different affinities, since mtSSB is involved in stabilising D-loops and in the maintenance of mtDNA [19]. Thus, it is plausible that impaired mtSSB binding to 16189C might be associated with a decreased mtDNA content, which has been reported in type 2 diabetes mellitus [21]. However, in our study there were no differences in peripheral blood mtDNA content between 16189T and 16189C carriers (data not shown). Given the potential influence of nuclear and mitochondrial genetic variations on mtDNA replication, it will be difficult to examine the effect of the T16189C polymorphism per se on mtDNA replication in vivo. Conplastic strains of rats with identical nuclear genomes but divergent mitochondrial genomes might be a useful tool to elucidate the relationship between mtDNA variants and metabolic phenotypes [22]. A recent study suggested that human cells exhibit two modes of mtDNA replication: one is a maintenance mode, regulated at the origin at $\mathrm{np} 57$, which is mainly responsible for maintaining the mtDNA copy number under steady-state conditions; the other is an induced mode, regulated at the origins and at the premature termination site at the $3^{\prime}$ end of the D-loop, which plays a major role in the initial recovery following mtDNA depletion [23]. Thus, it is possible that the different mtSSB binding affinities for the 16189 region change the rate of premature termination, thereby altering the speed of recovery following mtDNA damage.

Explanations for the differences in the risk of diabetes associated with the $16189 \mathrm{C}$ variant between Asian and European populations are not immediately clear. Interethnic differences in both nuclear and mitochondrial genomic structure and function and environmental factors may be important. The $16189 \mathrm{C}$ variant is found in haplogroups $\mathrm{H}$, $\mathrm{K}, \mathrm{N}, \mathrm{T}, \mathrm{U}, \mathrm{V}, \mathrm{X}$ and others in European populations [5]. In contrast, this genetic variant is found in the haplogroups $\mathrm{A}, \mathrm{B}, \mathrm{D}, \mathrm{F}, \mathrm{G}$ and others in Asian populations [11]. We recently identified the risk association of certain Asian haplogroups with resistance against or susceptibility to type 2 diabetes mellitus [24]. In this regard, mtDNA haplogroup has been implicated in disease expression in individuals with mitochondrial DNA mutation [25]. Indeed, the length heteroplasmy of the poly-C tract that results from variation 
at np 16189 has been shown to be influenced by different mtDNA haplogroups and nuclear factors [26]. Since we examined the mtSSB binding affinity at the D-loop region between np 16111 and 16260, we could not rule out the possibility that the binding affinity might be different in Europids than in Asians because of ethnic-specific variations other than the $16189 \mathrm{C}$ variant (or 16184-16193 poly-C tract) in this region. However, this is unlikely to be the case given the extremely polymorphic nature of the D-loop region around np 16189 (http://www.mitomap.org/cgi-bin/tbl6gen.pl, last accessed in January 2008).

Taken together, our data suggest that differences in nuclear and mitochondrial genetic backgrounds between Europids and Asians may contribute to differences in susceptibility to type 2 diabetes, often in combination with environmental factors. In support of this notion, increased BMI has been shown to be an aggravating factor for the development of diabetes in individuals with the $16189 \mathrm{C}$ variant [9].

Our study is subject to several limitations. First, the participants from Hong Kong were younger than those from other countries. The case cohort consists of 504 individuals with type 2 diabetes who were selected from the Hong Kong Diabetes Registry for early-onset diabetes (age at diagnosis $\leq 40$ years, mean age $33.0 \pm 5.7$ years). The controls consisted of 170 individuals with normal glucose tolerance (fasting plasma glucose $<6.1 \mathrm{mmol} / \mathrm{l}$ ) from the general population who were participating in a community-based cardiovascular risk screening programme and hospital staff. To exclude potential bias, we performed a meta-analysis excluding the Hong Kong participants. We found that the association between the $16189 \mathrm{C}$ variant and type 2 diabetes was still significant, both for our study only (OR 1.204, 95\% CI $1.02-1.42, p=0.028$ ) and for the overall meta-analysis (OR 1.310, 95\% CI 1.153-1.488, $p=3.5 \times 10^{-5}$ ).

Second, the number of participants in this study was much greater than in the other studies included in this metaanalysis, and so the result might be heavily influenced by the current study. In addition, publication bias may also affect the observed association between the $16189 \mathrm{C}$ variant and the risk of type 2 diabetes.

Third, in the meta-analysis of genetic association studies, a spurious association might be driven by population stratification [27]. Unfortunately, we did not genotype unlinked markers for genomic control, and are therefore not able to exclude this possibility at present.

Fourth, the association does not reach the accepted level of significance currently required for genetic association studies $\left(\sim 5 \times 10^{-7}\right)$, although our study showed the mtDNA $16189 \mathrm{C}$ variant was quite strongly associated with type 2 diabetes mellitus $\left(p=3 \times 10^{-6}\right)$.

Finally, the restriction enzyme MnlI is not specific to the 16189T variant and will also recognise other $\mathrm{T}$ sites within the 16184-16193 poly-C tract, even though most people have a $\mathrm{T}$ at np 16189. Thus, those who have a $\mathrm{C}$ at np 16189 and other T sites within the 16184-16193 poly-C tract might be erroneously classified as having $16189 \mathrm{~T}$ by MnII assay. In our study, we sequenced 290 randomly selected samples. All participants shown to have the $16189 \mathrm{C}$ variant by RFLP $(n=93)$ had an uninterrupted poly-C tract (mainly 10C, 11C or 12C). Among those with the $16189 \mathrm{~T}$ variant according to RFLP $(n=197)$, only three $(1 \%)$ were misclassified and shown to have the $16189 \mathrm{C}$ variant by direct sequencing. Moreover, like the wild-type DNA, these variants had a T at np 16187 and therefore had an interrupted 16184-16193 poly-C tract. Given that the $16189 \mathrm{C}$ variant is thought to exert its effect through the generation of a poly- $\mathrm{C}$ tract, misclassification of these rare sequence variants as wildtype (16189T) might not bias the association of the 16189C variant with type 2 diabetes in this large case-control study.

In conclusion, based on a large case-control cohort recruited from several Asian populations, the $16189 \mathrm{C}$ variant is associated with an increased risk of type 2 diabetes in Asians. This genetic variant, which is found more often in Asian than in European populations, also results in functional changes that may contribute to these interethnic differences in risk association.

Acknowledgements This work is supported by a grant from the Korea Health 21 R \& D Project (Ministry of Health and Welfare, Republic of Korea; 00-PJ3-PG6-GN07-001 to Y. M. Cho); by grant FPR05C1-110 of the 21C Frontier Functional Proteomics Project from the Korean Ministry of Science and Technology (to K. S. Park); by a grant from the Ministry of Information and Communication and the Institute for Information Technology Assessment through the Information Technology Leading R \& D Support Project (to H. K. Lee); by a grant (89-B-FA01-1-4) from the National Science Council of Taiwan (to L.-M. Chuang) and by the Research Grant Committee of the Hong Kong SAR Government and the Hong Kong Foundation for Research and Development, established under the Chinese University of Hong Kong (to J. C. N. Chan).

Duality of interest The authors declare that there is no duality of interest associated with this manuscript.

\section{References}

1. Petersen KF, Dufour S, Befroy D, Garcia R, Shulman GI (2004) Impaired mitochondrial activity in the insulin-resistant offspring of patients with type 2 diabetes. N Engl J Med 350:664-671

2. Maassen JA, 't Hart LM, Van Essen E et al (2004) Mitochondrial diabetes: molecular mechanisms and clinical presentation. Diabetes 53(Suppl 1):S103-S109

3. Wilson FH, Hariri A, Farhi A et al (2004) A cluster of metabolic defects caused by mutation in a mitochondrial tRNA. Science 306 : 1190-1194

4. Poulton J, Brown MS, Cooper A, Marchington DR, Phillips DI (1998) A common mitochondrial DNA variant is associated with insulin resistance in adult life. Diabetologia 41:54-58 
5. Poulton J, Luan J, Macaulay V, Hennings S, Mitchell J, Wareham NJ (2002) Type 2 diabetes is associated with a common mitochondrial variant: evidence from a population-based case-control study. Hum Mol Genet 11:1581-1583

6. Kim JH, Park KS, Cho YM et al (2002) The prevalence of the mitochondrial DNA 16189 variant in non-diabetic Korean adults and its association with higher fasting glucose and body mass index. Diabet Med 19:681-684

7. Tang DL, Zhou X, Li X, Zhao L, Liu F (2006) Variation of mitochondrial gene and the association with type 2 diabetes mellitus in a Chinese population. Diabetes Res Clin Pract 73:77-82

8. Momiyama Y, Furutani M, Suzuki Y et al (2003) A mitochondrial DNA variant associated with left ventricular hypertrophy in diabetes. Biochem Biophys Res Commun 312:858-864

9. Liou CW, Lin TK, Huei Weng $\mathrm{H}$ et al (2007) A common mitochondrial DNA variant and increased body mass index as associated factors for development of type 2 diabetes: additive effects of genetic and environmental factors. J Clin Endocrinol Metab 92:235-239

10. Chinnery PF, Elliott HR, Patel S et al (2005) Role of the mitochondrial DNA 16184-16193 poly-C tract in type 2 diabetes. Lancet 366:1650-1651

11. Tanaka M, Cabrera VM, Gonzalez AM et al (2004) Mitochondrial genome variation in eastern Asia and the peopling of Japan. Genome Res 14:1832-1850

12. Alberti KG, Zimmet PZ (1998) Definition, diagnosis and classification of diabetes mellitus and its complications. Part 1: diagnosis and classification of diabetes mellitus provisional report of a WHO consultation. Diabet Med 15:539-553

13. Choi YS, Ryu BK, Min HK, Lee SW, Pak YK (2005) Analysis of proteome bound to D-loop region of mitochondrial DNA by DNA-linked affinity chromatography and reverse-phase liquid chromatography/tandem mass spectrometry. Ann N Y Acad Sci 1042:88-100

14. Kim M-S, Choie W-S, Shin YS, Yu M-H, Lee S-W (2004) Development of ultra-high pressure capillary reverse-phase liquid chromatography/tandem mass spectrometry for high-sensitive and high-throughput proteomics. Bull Korean Chem Soc 25:1833-1839
15. Chomyn A (1996) Platelet-mediated transformation of human mitochondrial DNA-less cells. Methods Enzymol 264:334-339

16. Orlando V (2000) Mapping chromosomal proteins in vivo by formaldehyde-crosslinked-chromatin immunoprecipitation. Trends Biochem Sci 25:99-104

17. Borenstein MHL, Higgins J, Rothstein H (2005) Comprehensive meta-analysis, version 2. Biostat, Englewood

18. Hatchell EC, Colley SM, Beveridge DJ et al (2006) SLIRP, a small SRA binding protein, is a nuclear receptor corepressor. Mol Cell 22:657-668

19. Takamatsu C, Umeda S, Ohsato $T$ et al (2002) Regulation of mitochondrial D-loops by transcription factor A and single-stranded DNA-binding protein. EMBO Rep 3:451-456

20. Yasukawa T, Yang MY, Jacobs HT, Holt IJ (2005) A bidirectional origin of replication maps to the major noncoding region of human mitochondrial DNA. Mol Cell 18:651-662

21. Cho YM, Park KS, Lee HK (2007) Genetic factors related to mitochondrial function and risk of diabetes mellitus. Diabetes Res Clin Pract 77(Suppl 1):S172-S177

22. Pravenec M, Hyakukoku M, Houstek J et al (2007) Direct linkage of mitochondrial genome variation to risk factors for type 2 diabetes in conplastic strains. Genome Res 17:1319-1326

23. Fish J, Raule N, Attardi G (2004) Discovery of a major D-loop replication origin reveals two modes of human mtDNA synthesis. Science 306:2098-2101

24. Fuku N, Park KS, Yamada Y et al (2007) Mitochondrial haplogroup N9a confers resistance against type 2 diabetes in Asians. Am J Hum Genet 80:407-415

25. Brown MD, Starikovskaya E, Derbeneva O et al (2002) The role of mtDNA background in disease expression: a new primary LHON mutation associated with Western Eurasian haplogroup J. Hum Genet 110:130-138

26. Malik S, Sudoyo H, Pramoonjago P et al (2002) Nuclear mitochondrial interplay in the modulation of the homopolymeric tract length heteroplasmy in the control (D-loop) region of the mitochondrial DNA. Hum Genet 110:402-411

27. Munafo MR, Flint J (2004) Meta-analysis of genetic association studies. Trends Genet 20:439-444 